\title{
Heart Disease: Lifestyle, Knowledge, and Perception among Young Nigerian Adults
}

\author{
Ejiroghene Martha Umuerri'1,2 \\ 'Department of Medicine, Delta State University, Abraka, ²Department of Medicine, Delta State University Teaching Hospital, Oghara, Nigeria \\ ORCID: \\ Ejiroghene Martha Umuerri: https://orcid.org/0000-0001-8372-83
}

\section{Abstract}

Background: The proliferation of heart-unhealthy lifestyles may in part be responsible for the unabated scourge from heart disease. Assessments of knowledge and perception are key factors in curbing lifestyle-related diseases. Aims: The aim of the study is to determine the prevalence of heart-unhealthy lifestyles and its association with knowledge and perception of heart disease among young adults in Delta State, Nigeria. Settings and Design: A cross-sectional observational study conducted in Oghara, Nigeria. Materials and Methods: Three hundred healthy adults aged 18-35 years were recruited using the multistage sampling technique. The study instrument was a modified structured interviewer-administered questionnaire. Ethical approval was obtained before conducting the survey. Statistical Analysis Used: Obtained data were summarized and analyzed using SPSS version 22.0 software. Results: The response rate was 98\% (294/300): 103 males and 191 females. The mean and median age of the respondents was 27 years. Majority of the respondents had at least 6 years of formal education. Heart-unhealthy lifestyles were prevalent: lack of exercise (71.4\%), inadequate fruit intake (46.9\%), alcohol consumption (26.5\%), and tobacco smoking (19\%). The mean knowledge score for heart disease was 39.49\%. Using a score of 50\% as the benchmark for good knowledge, 59\% of the respondents had poor knowledge. Majority of the respondents did not perceive that they were at risk of heart disease. Conclusion: Heart-unhealthy lifestyles are common among young Nigerian adults. Knowledge of and self-perceived susceptibility to heart disease were poor in this study. There is a need for increased and refocused heart-health education at all ecological levels from early on in life.

Keywords: Health belief model, heart unhealthy lifestyle, knowledge, young adults

\section{INTRODUCTION}

The challenges from cardiovascular disease (CVD) are of foremost public health concern worldwide, more so in low- and middle-income countries. Nigeria, a lower-middle-income country, with a population of over 180 million persons as of 2016 had a proportional mortality of $11 \%$ accrued to CVD. ${ }^{[1]}$ A number of risk factors have been associated with the development of heart disease, some of which are lifestyle related (behavioral). The World Health Organization (WHO) has identified cigarette smoking, physical inactivity, harmful use of alcohol, and consumption of unhealthy diet as some heart-unhealthy behaviors. ${ }^{[2]}$ Several factors including rapid urbanization with increasing adoption of heart-unhealthy lifestyle, poor health-seeking behaviors, and a dearth in

Received: 21-Jun-19 Revision: 22-Aug-19 Accepted: 01-Sep-19

Published Online: 25-Nov-19

\begin{tabular}{|l|l|}
\hline \multicolumn{3}{|c|}{ Access this article online } \\
\hline Quick Response Code: & Website: \\
& http:/www.ijcva.com \\
\cline { 2 - 2 } & \\
&
\end{tabular}

policy initiatives (and implementation) promoting healthy living may contribute to the growing burden of CVD in these resource-limited countries. ${ }^{[2,3]}$

Technological advancement, one of the feats of globalization, inadvertently plays a critical role in influencing lifestyle choices that support physical inactivity. Aside from supporting a sedentary lifestyle, glamorous and enticing adverts on television (TV) and other media can negatively influence young adults to indulge in social habits such as smoking and alcohol consumption. Previous studies have reported unhealthy lifestyles such as cigarette smoking, harmful use of alcohol,

Address for correspondence: Dr. Ejiroghene Martha Umuerri, Department of Medicine, Delta State University Teaching Hospital, P.M.B. 07, Oghara, Nigeria. E-mail: umuerriejiro@gmail.com

This is an open access journal, and articles are distributed under the terms of the Creative Commons Attribution-NonCommercial-ShareAlike 4.0 License, which allows others to remix, tweak, and build upon the work non-commercially, as long as appropriate credit is given and the new creations are licensed under the identical terms.

For reprints contact: reprints@medknow.com

How to cite this article: Umuerri EM. Heart disease: Lifestyle, knowledge, and perception among young Nigerian adults. Int J Cardiovasc Acad 2019;5:134-40. 
and other psychoactive substances as seen more frequently among young adults compared to middle-aged and elderly persons. ${ }^{[4]}$ Furthermore, over the years, there is a paradigm shift in food culture. At present, young people commonly choose fast-foods and unhealthy snacks that are loaded with trans fat and salt over healthy foods such as fruits and vegetables. ${ }^{[5]}$

Not surprisingly, therefore, in a review of the global CVD burden, it was observed that the burden borne by young people showed an increasing trend. Similarly, in another review, young adults in Sub-Saharan Africa had a high prevalence of cardiovascular risk factors attributable to the cumulative effects of heart-unhealthy lifestyle compared to other regions of the world. ${ }^{[3]}$ Young adults in the Federal Republic of Nigeria are those aged between 18 and 35 years. ${ }^{[6]}$ However, the mean ages of the study population in many CVD-related epidemiological studies in Nigeria were over 35 years. ${ }^{[7,8]}$ Thus, the heart health of young adult Nigerians living in Nigeria can be described as largely understudied.

To curb the CVD scourge, the role of prevention, early detection, and treatment cannot be undermined. Adoption of heart-healthy lifestyle is a vital preventive strategy. Lack of knowledge and wrong perception of the relationship between heart-unhealthy behaviors and the occurrence of heart disease are two significant factors that can frustrate efforts at CVD prevention. The knowledge and perception of heart-unhealthy behaviors using the Health belief model (HBM) as conceptual framework among young Nigerian adults is generally lacking in the existing literature. The aim of this survey, therefore, is to determine the prevalence of heart-unhealthy lifestyles and the knowledge and perception of heart disease among young adults in Delta State, Nigeria.

\section{Materials and Methods}

\section{Study location}

The study location was Oghara, Delta State, South-South Nigeria. Oghara is a semi-urban agrarian town. It is also the administrative headquarters of Ethiope West Local Government Area (LGA), 1 of the 25 LGAs in Delta State. Each LGAs consist of wards with a different number of communities/settlements. Oghara has five wards with a total population of 159,385 .

\section{Study design}

The study design was cross-sectional and observational.

\section{Study population}

In Nigeria, young adults are persons aged between 18 and 35 years. ${ }^{[6]}$ To be included in this study, the potential study participant must be a healthy young adult who had resided in Oghara for at least 1 year and is willing to participate in the study voluntarily. Young adults who were visitors to or had lived less than a year in Oghara, and those who did not consent to take part in the study were excluded from the study.

The study population was recruited using a multistage sampling technique. First, the study location was selected by nonprobability convenience sampling. Following which, Ogharaefe-1, one of the five wards in Oghara, was selected by balloting, a simple random sampling technique. After that, a simple random sampling technique by balloting was again used to select streets from a sampling frame containing the list of all the streets in Ogharaefe-1 ward. Each selected street was regarded as a cluster. Finally, the study population who satisfied the inclusion criteria were recruited from households within the clusters until the sample size was reached.

\section{Sample size determination}

The minimum sample size for this study was calculated using the Cochrane formula. ${ }^{[9]}$ Assuming a confidence level of $95 \%$ and level of precision of $5 \%(0.05)$, the proportion of adults with hypertension in Oghara as $21 \%,{ }^{[7]}$ and a nonresponse rate of $10 \%$, the minimum sample size was 280 .

\section{Data collection}

Data were obtained from the study participants using a pretested interviewer-administered questionnaire adapted from previously validated questionnaires. Questions relating to lifestyle, knowledge, and perception were adapted from the WHO STEPwise questionnaire, ${ }^{[10]}$ the Heart Disease Knowledge Questionnaire, ${ }^{[1]}$ and the HBM, ${ }^{[12]}$ respectively.

\section{Heart-unhealthy lifestyles}

Four domains were assessed: tobacco smoking, physical inactivity, alcohol consumption, and unhealthy diet.

Ever smoked respondents are those that admitted having ever smoked tobacco, even if it were experimental puff(s), while current smokers were those who reported smoking within 1 month preceding the survey.

\section{Knowledge of heart disease}

Twenty items tested knowledge of heart disease, 11 of which were correct. A correctly identified item was scored as 1, while an incorrectly identified item attracted a score of 0 . Respondents that indicated "not sure" or "I don't know" were also scored 0 . Items unattended to by respondents were left out during the analysis. To determine the overall knowledge score, the sum of the correctly answered questions was computed and converted into percentages for each respondent. Respondents who scored $50 \%$ and above have good knowledge, while those with scores of $<50 \%$ have poor knowledge.

\section{Perception of heart disease and heart-healthy lifestyle}

The HBM was used to assess respondents' perception of the susceptibility to and the seriousness of heart disease and stroke. The reliability and internal consistency of the questions on perception were tested using Cronbach's alpha $(\alpha)$. Values $>0.7$ was regarded as acceptable interrelatedness, while $\alpha \leq 0.7$ may indicate poor interrelatedness, a small number, or heterogenicity of questions. Responses were ranked with a five-point Likert scale from strongly agree to strongly disagree.

\section{Data analysis}

Obtained data were checked for correctness, coded, and analyzed with the Statistical Product and Service Solutions 
version 22.0 software (IBM SPSS Inc. Chicago, Illinois, USA). The study population was summarized using frequencies, percentages, proportions, and 95\% confidence interval (CI). The associations between the level of knowledge of heart disease and sociodemographic data and lifestyle-related cardiovascular risk factors were tested using Chi-square analysis. Statistical significance was established if $P<0.05$.

\section{Ethical consideration}

A full committee ethical approval with number HREC/PAN/2017/066/0266 was obtained on December 7, 2017, from the Health Research Ethics Committees of Delta State University Teaching Hospital, Oghara, before the commencement of the survey. The University of Roehampton (Online) also provided an expedited ethics review approval prior to the survey. Written informed consent was obtained from the eligible study participants, and the conduct of the survey was guided by the tenets of the Helsinki declaration.

\section{RESULTS}

Data collection was done between February 2018 and March 2018. Of the 300 questionnaires distributed, 98\% were analyzed, as six had insufficient data.

\section{Sociodemographic profile}

The mean and median age of the study population was 27.01 (95\% CI: 26.39-27.63) and 27.0 years, respectively. About two-thirds of the study population were female. Half were single, and more than $90 \%$ had received at least 6 years of formal education [Table 1].

\section{Self-reported lifestyle-related cardiovascular risk factors Tobacco use}

Fifty-six (19.0\%) of the respondents reported that they had ever smoked. A significantly higher proportion of male respondents reported that they had ever smoked cigarette (28.2\% vs. $14.1 \%$, $\chi^{2}=8.529$, odds ratios [OR] [95\% CI] $=2.380[1.317-4.301]$, $P=0.003)$. Of the respondents who had ever smoked, $10.7 \%(6 / 56)$ were current smokers and smoked an average of 4 sticks of cigarette per day.

\begin{tabular}{llc}
\hline \multicolumn{2}{l}{ Table 1: Sociodemographic profile of respondents } \\
\hline Variables & Categories & Frequency (\%) \\
\hline Age (years) & $18-23$ & $96(32.7)$ \\
& $24-29$ & $82(27.9)$ \\
& $30-35$ & $116(39.5)$ \\
Sex & Male & $103(35.0)$ \\
& Female & $191(65.0)$ \\
Marital status & Single & $152(51.7)$ \\
& Married & $98(33.3)$ \\
& Cohabiting & $41(13.9)$ \\
& Others (unspecified) & $3(1.0)$ \\
Education (years) & $<6$ & $24(8.2)$ \\
& $6-12$ & $212(72.1)$ \\
& $>12$ & $58(19.7)$ \\
\hline
\end{tabular}

\section{Alcohol use}

Of the $180(61.2 \%)$ respondents that reported they had drunk alcohol ever, 78 (43.3\%) reported they had done so in the past 30 days. A higher proportion of males $(67 ; 65.0 \%)$ compared to females $(113 ; 59.0 \%)$ reported that they had drunk alcohol ever. The observed gender difference in the prevalence of alcohol consumption was not statistically significant $(P=0.323)$.

\section{Diet}

About half $(156 ; 53.1 \%)$ of the respondents reported that they ate fruits regularly. A greater proportion of male than female respondents $(63 ; 61.2 \%$ vs. $93 ; 48.7 \%)$ admitted to regular fruit intake, and the difference was statistically significant $\left(\chi^{2}=4.180\right.$, OR [95\% CI] $=1.660$ [1.019-2.702], $P=0.041)$. None of the respondents who admitted to regular consumption of fruits ate them every day. In a typical week, the number of days fruits were eaten by the respondents was: 1 day $(15 ; 9.6 \%), 2$ days $(57 ; 36.5 \%), 3$ days $(48 ; 30.8 \%)$, 4 days $(3 ; 1.9 \%), 5$ days $(12 ; 7.7 \%)$, and 6 days $(21 ; 13.5 \%)$. On a typical day, about half $(81 ; 51.9 \%)$ of the respondents who eat fruits regularly take two portions of fruit per day. The other respondents had either one portion $(60 ; 38.5 \%)$ or three portions $(15 ; 9.6 \%)$ of fruits on a typical day.

About $60 \%$ of the respondents add salt to already cooked food. This practice did not differ by sex $(P=0.612)$. Among the respondents that reported the use of added salt to already cooked food, $42(24.1 \%)$ does so always while it is often and rarely in $15(8.6 \%)$ and $117(67.2 \%)$ of the respondents, respectively.

\section{Exercise}

The majority (63.3\%) of the respondents walk at least $10 \mathrm{~min}$ in a day, and $91.9 \%(171 / 186)$ do so for at least $1 / 2 \mathrm{~h}$. However, $225(76.5 \%)$ of the respondents do not walk for travel. In the past month, other than regular jobs, $71.4 \%$ of the respondents did not engage in physical activity/exercise that caused an increase in breathing and heart rate for at least $10 \mathrm{~min}$ continuously. Male respondents $(27,26.2 \%)$ did not differ significantly from females $(57,29.8 \%)$ with regard to physical activity $(P=0.511)$. Among the respondents who engaged in physical activity that increase their respiratory or heart rates in the past month, the majority $(85.7 \%)$ did so either once $(39 / 84)$ or twice $(33 / 84)$ per week. Three $(3.6 \%)$ respondents each exercised 3, 4, 6, and 7 days in a typical week. Respondents who engage in sporting activities spend a mean time of $1.78 \mathrm{~h}$ on a typical day.

More than a quarter (87/294) of the respondents regularly view TV/computer screen. The mean time spent watching TV/computer was $2.9 \mathrm{~h}$ daily.

\section{Clustering of lifestyle-related risk factors}

The self-reported heart-unhealthy behaviors were clustered to determine the number of risk factors per respondent. The factors clustered were current smoking, consumption of alcohol in the past month, lack of regular intake of fruits, adding salt to 
already cooked food, and sedentary lifestyle. Six (2.0\%) of the respondents had no lifestyle-related cardiovascular risk factor. On the other hand, 100 (34.0\%), 61 (20.7\%), 124 (42.2\%), and $3(1.0 \%)$ of the respondents had $1,2,3$ and 4 risk factors, respectively.

\section{Knowledge of heart disease and stroke}

Of the 20 knowledge questions, only three were correctly answered by more than half of the respondents [Table 2].

The overall mean knowledge score $(\%)$ was $39.49( \pm 19.19)$ with a 95\% CI of 37.29-41.69. One hundred and seventy-four $(59.2 \%)$ of the respondents had poor knowledge score $(<50 \%)$.

\section{Knowledge of heart disease and sociodemographic characteristics of respondents}

Respondents' knowledge level of heart disease and stroke did not significantly differ with age, sex, marital status, or level of education [Table 3].

\section{Knowledge of heart disease and self-reported lifestyle-related cardiovascular risk factors}

The association between knowledge of heart disease and self-reported lifestyle-related cardiovascular risk factors among the respondents is as shown in Table 4.

\section{Perception of heart disease and stroke}

Whereas, the three questions on perceived susceptibility showed internal consistency and acceptable reliability ( $\alpha=0.858)$, the Cronbach's alpha for the two questions that addressed the perceived seriousness of heart disease and stroke only almost attained acceptable $(\alpha=0.666)$.

\section{Perceived susceptibility to heart disease or stroke}

Majority of the respondents had a negative perception of self-risk of heart disease or stroke. About three-quarters of the study population did not feel that they were at risk of heart disease or stroke; neither currently, shortly, nor sometime during their lifetime [Figure 1].

\section{Perceived seriousness of heart disease or stroke}

Half of the respondents did not agree that seeking medical checkup for asymptomatic heart disease was any less important than attending to other tangible problems, while about $30 \%$ agreed that heart disease and stroke might result in economic disability [Figure 2].

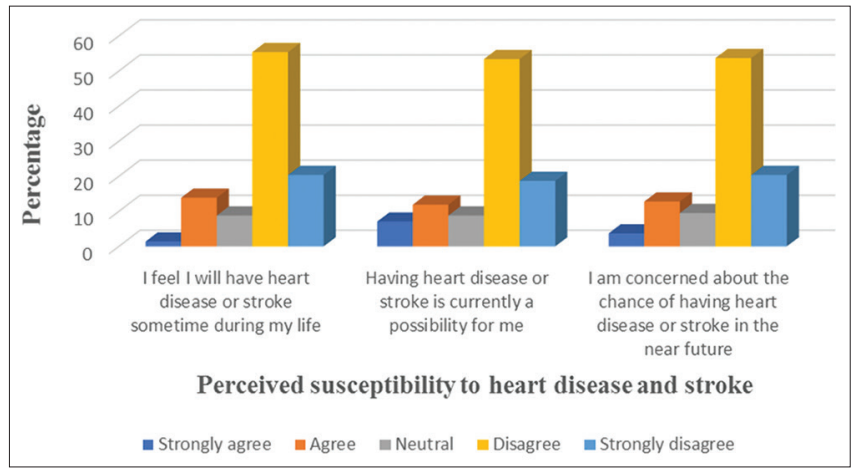

Figure 1: Perceived susceptibility to heart disease and stroke

Table 2: Respondents' knowledge of heart disease and stroke

\begin{tabular}{|c|c|c|c|c|}
\hline \multirow[t]{2}{*}{ Questions on knowledge of heart disease } & \multicolumn{3}{|c|}{ Respondents' answers } & \multirow{2}{*}{$\begin{array}{c}\text { Correct } \\
\text { response, } n(\%)\end{array}$} \\
\hline & True & False & I don’t know & \\
\hline A person always knows when they have heart disease & $106(36.1)$ & $111(37.8)$ & $77(26.2)$ & False: $111(37.8)$ \\
\hline If you have a family history of heart disease, you are at risk for developing heart disease & $108(36.7)$ & $118(40.1)$ & $68(23.1)$ & True: $108(36.7)$ \\
\hline Most women are likely to die from breast cancer than heart disease & $147(50.0)$ & $46(15.6)$ & $101(34.4)$ & False: $46(15.6)$ \\
\hline Smokers are more likely to die from lung cancer than heart disease or stroke & $152(51.7)$ & $79(26.9)$ & $63(21.4)$ & False: 79 (26.9) \\
\hline A person who stops smoking will lower their risk of developing heart disease & $179(60.9)$ & $60(20.4)$ & $55(18.7)$ & True: $179(60.9)$ \\
\hline Regular heavy alcohol intake lowers the risk of developing heart disease & $115(39.1)$ & $85(28.9)$ & $94(32.0)$ & False: 85 (28.9) \\
\hline High blood pressure is a risk factor for heart disease & $115(39.1)$ & $53(18.0)$ & $126(42.9)$ & True: $115(39.1)$ \\
\hline The most important cause of stroke is stress & $95(32.3)$ & $103(35.0)$ & $96(32.7)$ & False: $103(35.0)$ \\
\hline Sudden inability to move one half of the body is a common sign of stroke & $144(49.0)$ & $48(16.3)$ & $102(34.7)$ & True: $144(49.0)$ \\
\hline High cholesterol is a risk factor for developing heart disease & $102(34.7)$ & $49(16.7)$ & $143(48.6)$ & True: $102(34.7)$ \\
\hline Eating fatty foods does not affect blood cholesterol levels & $113(38.4)$ & $82(27.9)$ & $99(33.7)$ & False: $82(27.9)$ \\
\hline Trans fats are healthier for the heart than most other kinds of fats & $100(34.0)$ & $80(27.2)$ & $114(38.8)$ & False: $80(27.2)$ \\
\hline Most of the cholesterol in an egg is in the white part of the egg & $94(32.0)$ & $118(40.1)$ & $82(27.9)$ & False: $118(40.1)$ \\
\hline Eating a lot of red meat increases the risk of heart disease & $107(36.4)$ & $72(24.5)$ & $115(39.1)$ & True: 107 (36.4) \\
\hline Being overweight increases a person's risk for heart disease & $133(45.2)$ & $51(17.3)$ & $110(37.4)$ & True: 133 (45.2) \\
\hline Sitting for long hours increases the risk of heart disease & $137(46.6)$ & $90(30.6)$ & $67(22.8)$ & True: 137 (46.6) \\
\hline Regular physical activity will lower a person's chance of getting heart disease & $178(60.5)$ & $49(16.7)$ & $67(22.8)$ & True: $178(60.5)$ \\
\hline $\begin{array}{l}\text { Only exercising at a gym or in an exercise class will lower a person's chance of } \\
\text { developing heart disease }\end{array}$ & $46(15.6)$ & $169(57.5)$ & $79(26.9)$ & False: $169(57.5)$ \\
\hline Diabetes is a risk factor for developing heart disease & $100(34.0)$ & $60(20.4)$ & $134(45.6)$ & True: $100(34.0)$ \\
\hline $\begin{array}{l}\text { A person who has diabetes can reduce their risk of developing heart disease if they keep } \\
\text { their blood sugar levels under control }\end{array}$ & $146(49.7)$ & $84(28.6)$ & $64(21.8)$ & True: $146(49.7)$ \\
\hline
\end{tabular}




\section{Discussion}

This study has shown that young Nigerian adults commonly engage in lifestyles that put their heart health at risk. Almost all the respondents $(98.0 \%)$ had at least one lifestyle-related cardiovascular risk factor, and more than $40 \%$ had a cluster of three lifestyle-related risk factors. Thus, corroborating earlier reports that the presence of multiple risk factors for heart disease

\begin{tabular}{|c|c|c|c|}
\hline \multirow{2}{*}{$\begin{array}{l}\text { Sociodemographic } \\
\text { characteristic }\end{array}$} & \multirow[t]{2}{*}{ Category } & \multicolumn{2}{|c|}{ Knowledge level } \\
\hline & & $\begin{array}{c}\text { Poor }(n=174 ; \\
59.2 \%)\end{array}$ & $\begin{array}{c}\text { Good }(n=120 ; \\
40.8 \%)\end{array}$ \\
\hline \multirow[t]{4}{*}{ Age group (year) } & $18-23$ & $56(32.2)$ & $40(33.3)$ \\
\hline & $24-29$ & $53(30.5)$ & $29(24.2)$ \\
\hline & $30-35$ & $65(37.4)$ & $51(42.5)$ \\
\hline & \multicolumn{3}{|c|}{$\chi^{2}=1.513, \mathrm{df}=2, P=0.469$} \\
\hline \multirow[t]{3}{*}{ Sex } & Male & $66(37.9)$ & $37(30.8)$ \\
\hline & Female & $108(62.1)$ & $83(69.2)$ \\
\hline & \multicolumn{3}{|c|}{$\chi^{2}=1.572, \mathrm{df}=1, P=0.210$} \\
\hline \multirow[t]{5}{*}{ Marital status } & Single & $99(56.9)$ & $53(44.2)$ \\
\hline & Married & $55(31.6)$ & $43(35.8)$ \\
\hline & Co-habiting & $18(10.3)$ & $23(19.2)$ \\
\hline & Others & $2(1.1)$ & $1(0.8)$ \\
\hline & \multicolumn{3}{|c|}{$\chi^{2}=6.639, \mathrm{df}=3, P=0.084$} \\
\hline \multirow{4}{*}{$\begin{array}{l}\text { Highest level of } \\
\text { education (years) }\end{array}$} & $<6$ & $15(8.6)$ & $9(7.5)$ \\
\hline & $6-12$ & $125(71.8)$ & $87(72.5)$ \\
\hline & $>12$ & $34(19.5)$ & $24(20.0)$ \\
\hline & \multicolumn{3}{|c|}{$\chi^{2}=0.121, \mathrm{df}=2, P=0.941$} \\
\hline
\end{tabular}

and stroke are not uncommon in individuals. ${ }^{[8,13]}$ Unfortunately, cumulative indulgence in heart-unhealthy lifestyles, especially from a young age, may lead to other physiologic/metabolic cardiovascular risk factors such as obesity, hypertension, dyslipidemia, and type 2 diabetes mellitus. ${ }^{[2]}$

Compared to other countries in Sub-Saharan Africa, the prevalence of smoking in Nigeria is low. ${ }^{[14]}$ In Nigeria, a report of the 2012 Global Adult Tobacco Survey (GATS) shows that initiation of tobacco smoking was commonly by adolescents and young adults aged $<25$ years. ${ }^{[15]}$ Although tobacco smoking was the least common heart-unhealthy lifestyle encountered in this survey, it was not surprising that one-in-five of the young adults admitted to ever smoked. The prevalence of regular current smokers in this study $(2.0 \%)$ was lower than the $4.4 \%$ reported by the 2012 GATS in Nigeria among adults aged

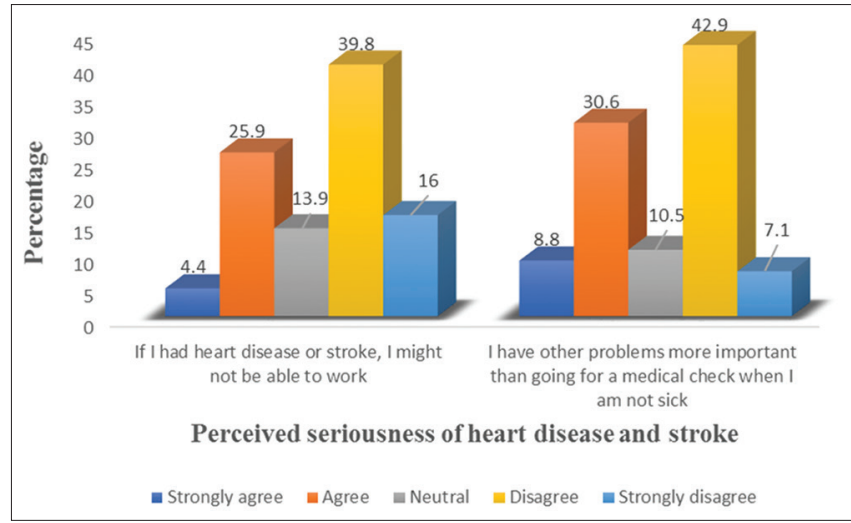

Figure 2: Perceived seriousness of heart disease and stroke

\begin{tabular}{|c|c|c|c|c|c|c|}
\hline Variable & Category & Poor knowledge $(n=174)$ & Good knowledge $(n=120)$ & Total $(n=294)$ & $\chi^{2}$ & $P$ \\
\hline \multirow[t]{6}{*}{ Smoking } & Ever smoked & & & & & \\
\hline & Yes & $45(80.4)$ & $11(19.6)$ & $56(19.0)$ & 12.838 & $<0.001$ \\
\hline & No & $129(54.2)$ & $109(45.8)$ & $238(81.0)$ & & \\
\hline & Current smokers & & & & & \\
\hline & Yes & $3(50.0)$ & $3(50.0)$ & $6(2.0)$ & 0.214 & 0.644 \\
\hline & No & $171(59.4)$ & $117(40.6)$ & $288(98.0)$ & & \\
\hline \multirow{6}{*}{$\begin{array}{l}\text { Alcohol } \\
\text { use }\end{array}$} & Ever drank alcohol & & & & & \\
\hline & Yes & $130(72.2)$ & $50(27.8)$ & $180(61.2)$ & 32.669 & $<0.001$ \\
\hline & No & $44(38.6)$ & $70(61.4)$ & $114(38.8)$ & & \\
\hline & Drank alcohol in the past 30 days & & & & & \\
\hline & Yes & $72(92.3)$ & $6(7.7)$ & $78(26.5)$ & 48.221 & $<0.001$ \\
\hline & No & $102(47.3)$ & $114(52.8)$ & $216(73.5)$ & & \\
\hline \multirow[t]{6}{*}{ Diet } & Eat fruits regularly & & & & & \\
\hline & Yes & $106(67.9)$ & $50(32.1)$ & $156(53.1)$ & 10.570 & 0.001 \\
\hline & No & $68(49.3)$ & $70(50.7)$ & $138(46.9)$ & & \\
\hline & Added salt* & & & & & \\
\hline & Yes & $127(73.0)$ & $47(27.0)$ & $174(59.2)$ & 33.631 & $<0.001$ \\
\hline & No & $47(39.2)$ & $73(60.8)$ & $120(40.8)$ & & \\
\hline \multirow[t]{3}{*}{ Exercise } & Physical activity in the past month ${ }^{\dagger}$ & & & & & \\
\hline & Yes & $52(61.9)$ & $32(38.1)$ & $84(28.6)$ & 0.360 & 0.548 \\
\hline & No & $122(58.1)$ & $88(41.9)$ & $210(71.4)$ & & \\
\hline
\end{tabular}

*Add salt to already cooked food, ${ }^{\top}$ Physical activity that increases heart rate or breathing for at least 10 min 
15 years and older. ${ }^{[15]}$ The difference may be accounted for by the inclusion of older adults in the 2012 GATS. The 2012 GATS estimates show that the prevalence of current smoking was highest among older adults aged $35-44$ years. ${ }^{[15]}$ In a community-based survey in Delta State, Nigeria, the proportion of current daily smokers was least among the young adults aged between 18 and 27 years. ${ }^{[7]}$

A significantly higher percentage of male respondents in this survey reported a history of smoking. Previous studies have reported similar gender differences in the prevalence of smoking among young and older adults in Nigeria. ${ }^{[15]}$ The observed gender differences may be attributable to stigmatizing social norms that limit smoking among females, especially in public places in Nigeria.

In this study, many of the respondents reported drinking alcohol, and more than two-fifths of them had done so in the past month. Consumption of alcoholic beverages was without prejudice to sex. It is not uncommon for young and older adults to consume alcoholic beverages in Sub-Saharan Africa. ${ }^{[7,16]}$ For example, in present-day Nigeria, young adults indulge in drinking alcoholic beverages without social, legal, or cultural restrictions as long as they do not become intoxicated or recourse to social vices. ${ }^{[17]}$ Peer pressure and enticing advertisement strongly influence young people to consume alcoholic beverages. ${ }^{[17]}$ Indeed, among young adults globally, alcohol is one of the most frequently consumed psychoactive substances. ${ }^{[16,18]}$ Heavy alcohol consumption is an established cardiovascular risk factor. Previous studies show that young adults frequently drink heavily and in binges. ${ }^{[19]}$ However, the present study did not estimate the quantity of alcohol consumed by respondents. Thus, inferences of alcohol misuse or abuse are limited in this study.

Consumption of unhealthy diet was typical in this study. Low consumption of fruits and vegetables was rife. About half of the respondents indicated they do not eat fruits regularly, while none of the others ate up to the recommended five portions daily by the WHO. ${ }^{[20]}$ Other studies have also reported low intake of fruits among young adults. ${ }^{[21]}$ Increased salt intake is another dietary cardiovascular risk factor. Adding salt to already prepared food is an unhealthy practice that increases the risk of hypertension. In this survey, majority of the respondents admitted to adding salt to already cooked food, howbeit rarely. Although not assessed in the index survey, consumption of salty snacks and processed foods and frequent patronage of fast-food vendors also increase dietary salt intake among young adults.

Physical inactivity was rife in this study and without gender bias. Majority of the young adults reported that they did not walk for travel or engage in recreational physical activities. Adegoke and Oyeyemi also reported a high prevalence of physical inactivity among young Nigerian adults. ${ }^{[22]}$ However, females were more physically inactive in their study. ${ }^{[22]}$ Screen time from watching TV, video games, and other electronic devices contribute to physical inactivity. Although there is no standard or recommended screen time for adults in Nigeria, the mean time spent watching TV daily in this survey was almost $3 \mathrm{~h}$.

Knowledge empowers people to make informed and healthy choices. This study has shown an overall poor knowledge of heart disease among young Nigerian adults living in Delta State. Previous studies among young adults have reported different levels of knowledge of CVD and its risk factors. ${ }^{[23-26]}$ Whereas, a similarly poor level of knowledge was described among the African-Americans in the Coronary Artery Risk Development in Young Adults (CARDIA) study, ${ }^{[24]}$ Ibrahim et $a l .{ }^{[26]}$ reported high knowledge levels among young adults in Malaysia. Akin to observations by Winham and Jones, ${ }^{[23]}$ the respondents' knowledge of various cardiovascular risk factors differed in this study. Majority of the respondents did not correctly identify diabetes, hypertension, hyperlipidemia, overweight, unhealthy diet, and harmful use of alcohol as risk factors for heart disease. On the other hand, regular physical activity and cessation of smoking were correctly identified by about $60 \%$ of the study population as factors that can lower the risk of heart disease.

The index study did not show any association between level of knowledge and sociodemographic factors (age, sex, marital status, and level of education). A similar observation was reported by Awotidebe et al. in a previous study of female undergraduates in a Nigerian university. ${ }^{[25]}$ Furthermore, in another study of young Malaysian undergraduates, a lack of association between knowledge of CVD risk factors and sex was observed. ${ }^{[26]}$ In contrast, however, the CARDIA study reported an association between level of education and knowledge of heart disease. ${ }^{[24]}$

Majority of the respondents in this study with a poor level of knowledge of heart disease and its behavioral risk factors engaged in heart-unhealthy lifestyles. This observation contrasts with the findings of Ibrahim et al., ${ }^{[26]}$ in which the practice of heart-unhealthy lifestyle was prevalent despite a high level of knowledge of heart disease. Indeed, other studies have reported that young adults' adoption of heart-healthy lifestyles to be relatively low in comparison to their knowledge of and even the presence of cardiovascular risk factors. ${ }^{[27,28]}$ Perhaps, the behavior gap may be due to the low self-perceived risk of heart disease. ${ }^{[29]}$

Knowledge alone is not enough to influence the adoption of a healthy lifestyle. Indeed, risk perception drives risk-reduction strategies. Compared to older adults, young adults generally perceive their health as good. ${ }^{[27]}$ In this study, almost all the respondent felt their health was good. Indeed, more than half of them reported that their general health status was excellent. However, using the HBM to explore the perception of heart disease, underestimation of perceived susceptibility to heart disease was rife in this study. Akin to the present study, Green et $a l .^{[30]}$ reported the inaccurate perception of heart disease risk among young adults. The perceived seriousness of heart disease was also low in this study. 


\section{ConcLusion}

This study shows that young adults in Delta State, Nigeria, commonly engage in behaviors that can compromise their lifetime heart health. Multiple lifestyle-related cardiovascular risk factors were common among the individuals studied. The knowledge level of heart disease was poor among young adults in this study, irrespective of their sex and educational status. Majority of the respondents had a negative perception of susceptibility to and seriousness of heart disease. This study highlights the need for intensified health education and enlightenment campaigns to address the identified gaps cannot be overemphasized.

\section{Financial support and sponsorship}

Nil.

\section{Conflicts of interest}

There are no conflicts of interest.

\section{References}

1. World Health Organization. Non-Communicable Disease Country Profiles. Nigeria: World Health Organization; 2018. Available from: https://www.who.int/nmh/countries/nga_en.pdf?ua=1. [Last accessed on 2019 May 21].

2. World Health Organization. Cardio Vascular Diseases. Available from: https:/www.who.int/news-room/fact-sheets/detail/ cardiovascular-diseases-(cvds). [Last accessed on 2018 Aug 08].

3. Steyn K, Damasceno A. Lifestyle and related risk factors for chronic diseases. In: Jamison DT, Feachem RG, Makgoba MW, Bos ER, Baingana FK, Hofman KJ, et al. editors. Disease and Mortality in Sub-Saharan Africa. $2^{\text {nd }}$ ed. Washington (DC): World Bank; 2006. Available from: https:/www.ncbi.nlm.nih.gov/books/ NBK2290/\#A1627. [Last accessed on 2018 Aug 27].

4. Saint Onge JM, Krueger PM. Health lifestyle behaviors among U.S. Adults. SSM Popul Health 2017;3:89-98.

5. Clayton P, Rowbotham J. How the mid-Victorians worked, ate and died. Int J Environ Res Public Health 2009;6:1235-53.

6. Second National Youth Policy Document of the Federal Republic of Nigeria; 2009. Available from: http://www.youthpolicy.org/national/ Nigeria_2009_National_Youth_Policy.pdf. [Last accessed on 2017 Oct $10]$

7. Ibekwe R. Modifiable risk factors of hypertension and socio-demographic profile in Oghara, Delta state; prevalence and correlates. Ann Med Health Sci Res 2015;5:71-7.

8. Oladapo OO, Salako L, Sodiq O, Shoyinka K, Adedapo K, Falase AO, et al. A prevalence of cardiometabolic risk factors among a rural Yoruba South-Western Nigerian population: A population-based survey. Cardiovasc J Afr 2010;21:26-31.

9. Araoye MO. Research Methodology with Statistics for Health Social Sciences. Ilorin: Nathadex Publishers; 2009.

10. World Health Organization. The WHO Stepwise approach to chronic disease risk factor surveillance (STEPS). Geneva, Switzerland: World Health Organization; 2003. Available from: http://www.who.int/chp/ steps/STEPS_Instrument_v2.1.pdf. [Last accessed on 2017 Oct 10].

11. Bergman HE, Reeve BB, Moser RP, Scholl S, Klein WM. Development of a comprehensive heart disease knowledge questionnaire. Am J Health Educ 2011;42:74-87.

12. Champion VL, Skinner CS. The health belief model. In: Glanz K, Rimer BK, Viswanath K, editors. Health Behaviour and Health
Education: Theory, Research and Practice. $4^{\text {th }}$ ed. San Francisco, CA: Jossey-Bass; 2008.

13. Yusuf S, Hawken S, Ounpuu S, Dans T, Avezum A, Lanas F, et al. Effect of potentially modifiable risk factors associated with myocardial infarction in 52 countries (the INTERHEART study): Case-control study. Lancet 2004;364:937-52.

14. Brathwaite R, Addo J, Smeeth L, Lock K. A systematic review of tobacco smoking prevalence and description of tobacco control strategies in Sub-Saharan African countries; 2007 to 2014. PLoS One 2015;10:e0132401.

15. Adeniji F, Bamgboye E, van Walbeek C. Smoking in Nigeria: Estimates from the global adult tobacco survey (GATS) 2012. J Sci Res Rep 2016;11:1-10.

16. Mbutiwi FI, Lepira FB, Mbutiwi TL, Kumakuma DK, Kumbukama GK, Sylvestre MP. Prevalence and sex-specific distribution of cardiovascular risk factors in university students in an urban-rural environment of the democratic republic of the Congo. J Community Health 2018;43:761-7.

17. Dumbili EW. Patterns and determinants of alcohol use among Nigerian university students: An overview of recent developments. Afr J Drug Alcohol Stud 2013;12:29-51.

18. Görgülü Y, Çakir D, Sönmez MB, Köse Çinar R, Vardar ME. Alcohol and psychoactive substance use among University students in Edirne and related parameters. Noro Psikiyatr Ars 2016;53:163-8.

19. Krieger H, Young CM, Anthenien AM, Neighbors C. The epidemiology of binge drinking among college-age individuals in the United States. Alcohol Res 2018;39:23-30.

20. World Health Organization. Global Strategy on Diet, Physical Activity and Health: Promoting Fruit and Vegetable Consumption around the World. World Health Organization; 2018. Available from: http://www who.int/dietphysicalactivity/fruit/en/. [Last accessed on 2018 May 09].

21. Layade AA, Adeoye IB. Fruit and vegetable consumption among students of tertiary institutions in Oyo state. Russ J Agric Soc Econ Sci 2014;6:3-8.

22. Adegoke BO, Oyeyemi AL. Physical inactivity in Nigerian young adults: Prevalence and socio-demographic correlates. J Phys Act Health 2011;8:1135-42

23. Winham DM, Jones KM. Knowledge of young African American adults about heart disease: A cross-sectional survey. BMC Public Health 2011;11:248.

24. Lynch EB, Liu K, Kiefe CI, Greenland P. Cardiovascular disease risk factor knowledge in young adults and 10-year change in risk factors: The coronary artery risk development in young adults (CARDIA) study. Am J Epidemiol 2006;164:1171-9.

25. Awotidebe TO, Adedoyin RA, Fatoogun B, Adeyeye V, Mbada CE, Akinola OT, et al. An assessment of knowledge of Nigerian female undergraduates on obesity as a risk factor for cardiovascular disease in women. Am J Health Res 2014;2:50-5.

26. Ibrahim MM, Rahman NA, Rahman NI, Haque M. Knowledge, attitude and practice of Malaysian public university students on risk factors for cardiovascular diseases. J Appl Pharm Sci 2016;6:56-63.

27. Lawrence EM, Mollborn S, Hummer RA. Health lifestyles across the transition to adulthood: Implications for health. Soc Sci Med 2017; 193:23-32

28. Tasdemir-Ozdes A, Strickland-Hughes CM, Bluck S, Ebner NC. Future perspective and healthy lifestyle choices in adulthood. Psychol Aging 2016;31:618-30.

29. Tran DT, Zimmerman LM, Kupzyk KA, Shurmur SW, Pullen CH, Yates BC. Cardiovascular risk factors among college students: Knowledge, perception, and risk assessment. J Am Coll Health 2017;65:158-67.

30. Green JS, Grant M, Hill KL, Brizzolara J, Belmont B. Heart disease risk perception in college men and women. J Am Coll Health 2003;51:207-11 